\title{
Defining Effective Teaching in Environmental Education: A Georgia 4-H Case Study
}

\author{
Lillian G. Meighan, Nicholas E. Fuhrman \\ University of Georgia
}

\begin{abstract}
Many studies have examined the positive learning outcomes of environmental education (EE), yet few have questioned the means for achieving such outcomes through non-formal teaching methods. Six interviews and four observations were conducted with 4-H environmental educators in Georgia. Study participants defined effective instruction in Georgia 4-H $\mathrm{EE}$ as novel and student-centered, where the educator utilizes their own distinct teaching styles, management of the learning environment, and extra resources while capitalizing on teachable moments. Educators worked to create both personal and environmental connections to inspire students to pursue science and environmental careers. EE trainings should prepare educators with either natural science or non-science backgrounds with teaching practice opportunities, extra curriculum materials, and co-worker support to maximize benefits for environmental educators and learners.
\end{abstract}

Keywords: effective teaching, teaching methods, non-formal education

\section{Introduction}

Environmental education (EE) works to move learners from awareness to action. Specifically, EE aims to create a population that is aware of and equipped with knowledge and skills to create solutions for current and future environmental problems (North American Association for Environmental Education, 2010; United Nations Educational, Scientific, and Cultural Organization-United Nations Environment Program, 1978). As a discipline, EE was founded on learnercentered techniques to drive positive environmental action (UNESCO-UNEP, 1978) and has remained "learner-centered, providing students with opportunities to construct their own understandings through hands-on, minds-on investigations" (p.1) through active experiential education (NAAEE, 2010). Agricultural educators and environmental educators have much in common. Both types of educators often work in outdoor environments and other environments which are unfamiliar to their learners (Shumacher, Fuhrman, \& Duncan, 2012). Both use instructional techniques to move learners from awareness of environmental issues to taking the necessary action to address such issues. The importance of this type of education makes it critical to identify the most "effective" instructional techniques in these environments essential to agricultural and environmental educators. The Natural Resources Systems Pathway of the National Career Clusters Framework highlights the importance of using oral communications skills to express and interpret information to various audiences. Although Georgia 4-H environmental educators are often hired following graduation from career and technical agricultural education-focused majors with varying levels of science and non-science backgrounds, little is known about how these new educators view "effective" teaching.

Environmental education programs have resulted in changes in many aspects of students' lives. Students who participate in EE programs have exhibited greater knowledge (Ballantyne \& Packer, 2002) and application of knowledge across multiple contexts, while being able to communicate such knowledge to others effectively (Chambers \& Radbourne, 2014). Positive correlations also exist between standardized testing scores and programs which integrated $\mathrm{EE}$ into the curriculum (Lieberman \& Hoody, 1998). Further, an ethic of care and stewardship for the environment has been recorded in students who participated in EE (Ballantyne \& Packer, 2002). However, the training, teaching methods, and other program inputs have remained unexplored in the EE literature base (Digby \& Ferrari, 2007; Franz, Garst, Baughman, Smith, \& Peters, 2009; Goldsmith \& Rubenstein, 2017). Recently, researchers documented overarching outcomes and goals of EE, yet a gap in the literature still exists regarding a conceptualized framework for effective teaching in these often nonformal learning environments that are more novel than the traditional classroom environment (Goldsmith \& Rubenstein, 2017). In earlier works, others have noted the need for additional research on the "social, physical, and contextual elements of positive change settings" (Franz 
et al., 2009) such as those experienced by youth participants engaging in EE through 4-H center programs. Given the absence of a discussion of effective teaching practices through the lens of environmental educators working in 4-H EE programs, the purpose of this study was to identify how Georgia 4-H environmental educators define "effective" instructional practices in their work to promote EE at Georgia 4-H centers.

\section{Literature Review}

Formal and non-formal education remains distinctly different in delivery and setting. Formal education can be described as a hierarchically structured, chronological education system that typically covers primary school to the university-level and is usually set inside a traditional classroom (Coombs \& Ahmed, 1974). Non-formal education has been considered to be any organized educational activity outside of the established formal system and is usually set in areas not familiar to the learner (Coombs \& Ahmed, 1974). Environmental education and career and technical agricultural education often operate in both settings and share many similarities. Although traditionally not explored in the career and technical agricultural education research base, Shumacher et al. (2012) encouraged synergy between the disciplines because both are rooted in experiential learning, are often place-based, and capitalize on using the teaching environment as a conduit for student learning.

While teacher behaviors have been established in traditional classrooms, little research surround the overarching teaching methods of non-formal educators. In the formal classroom, teacher behaviors which are considered effective include: clarity, variability, enthusiasm, task oriented, and providing the opportunity to learn (Rosenshine \& Furst, 1971; Barrick \& Thoron, 2016; Roberts, Dooley, Harlin, \& Murphrey, 2007). Characteristics of educators in non-formal settings include: participant centered, able to comfort students, ability to assess and appreciate differences in the audience, and has a broad knowledge of many content areas (Taylor \& Caldarelli, 2004). Formal educational teaching methods have been well established, developed, and documented within the career and technical agricultural education discipline (Roshenshine \& Furst, 1971; Roberts, Dooley, Harlin, \& Murphrey, 2007; Minor, Onwuegbuzie, Witcher, \& James, 2002), while non-formal education has remained relatively unexplored, especially in the context of EE (Smith, 2002).

The 4-H youth development programs are operated within the Cooperative Extension System of land-grant universities (National 4-H, 2015). As the largest youth Figure 1. Triadic reciprocity model (Bandura, 2004). development organization in the United States, 4-H has served over 6 million youth (National 4-H, 2015). The 4$\mathrm{H}$ organization "empowers young people with the skills to lead for a lifetime" (para. 4) by utilizing research-based curriculum and pairing youth with a caring adult who engages them in meaningful, hands-on, experiential learning opportunities (National 4-H, 2015). A recent longitudinal youth development study found youth involved in 4-H were four times more likely to give back to their communities, two times more likely to make healthier choices, and two times more likely to participate in STEM activities (Lerner \& Lerner, 2013). Residential programming in $4-\mathrm{H}$ includes summer camp and $\mathrm{EE}$. Both programs immerse students in an overnight learning experience at a 4-H center typically focused on STEM subject areas (Georgia 4-H, 2016b; Georgia 4-H, 2016c). Although the current literature base has emphasized 4-H summer camp impacts on youth, very few studies have been conducted on 4-H EE programming and the teaching practices that seem to produce the most beneficial learning experiences for participants.

Environmental education programming plays a major role in fulfilling the Georgia 4-H mission "to assist youth in acquiring knowledge, developing life skills, and forming attitudes that will enable them to become selfdirecting, productive, and contributing members of society" (Georgia 4-H, 2016a, Para 2). Georgia EE programming includes overnight and day programming that emphasizes geographic, science, and environmental curriculum aligned with Georgia Performance Standards (Georgia 4-H, 2016a). This study aimed to define effective EE teaching from the perspective of environmental educators within Georgia 4-H EE.

\section{Theoretical Framework}

The triadic reciprocity model (Bandura, 2004), rooted in social learning theory, was identified following qualitative data analysis to help explain the findings of this study. Social learning theory posits that "psychological functioning involves a continuous reciprocal interaction between behavior and its controlling conditions," personal characteristics, and the environment (Bandura, 1971, p. 39). Bandura (2004) noted that behavior did not fall within a linear process, but rather was a reciprocal process with three distinct factors. The three factors included individual behaviors, personal characteristics, and the environment where learning occurred (Figure 1). However, the three factors may not always be of equal strength, nor are they fixed in reciprocal causation. Depending on the context of the situation, "the relative influence exerted by the three sources of interlocking determinants will vary for different activities, different individuals, and different circumstances" (Bandura, 2004, p. 27). 


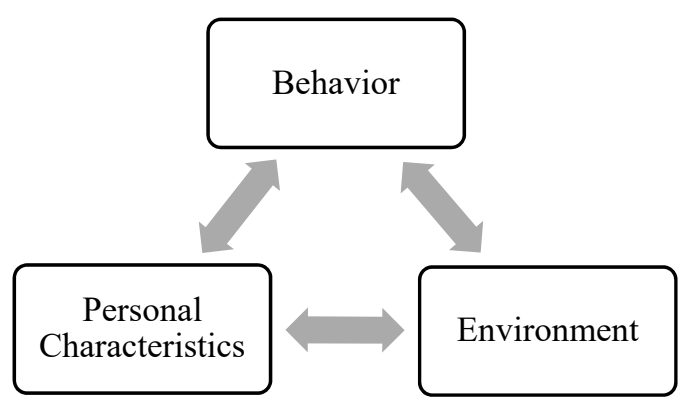

Figure 1. Triadic reciprocity model (Bandura, 2004).

Researchers in this study applied the triadic reciprocity model (TRM) to interpret the data and draw conclusions surrounding the environmental educators' perceptions of effective teaching in EE. Teaching methods, educator characteristics, and the teaching environment represented behaviors, personal characteristics, and environment respectively (Figure 1). Few studies have applied TRM to the context of "effective" teaching in environments typical of those used in evaluation. As such, this theory may aid in future studies regarding effective teaching in non-formal environments.

\section{Methods}

A qualitative research design was selected to describe how Georgia 4-H environmental educators defined "effective" teaching practices. Three 4-H centers in Georgia were selected for exploration through this case study. A center was selected from each physiographic region of Georgia (Figure 2). Burton 4-H Center, Rock Eagle 4-H Center, and Wahsega 4-H Center represent the coastal, piedmont, and Blue Ridge physiographic regions of the state, respectively. The different physiographic regions of the state provided different lesson opportunities due to the differences in local surrounding natural ecosystem and culture.

After obtaining University of Georgia IRB approval, two educators, one with a natural science background (i.e., Wildlife Science) and one with a non-natural science background (i.e., English), were interviewed from each of the three selected 4-H centers (Error! Reference source not found.). The Wahsega staff did not include a non-natural science background educator; therefore, two natural science educators were interviewed. Additionally, study participants at Rock Eagle and Burton 4-H Centers were observed teaching one full lesson to identify if behavior in a real EE teaching environment matched the effective teaching definition shared by study participants. Wahsega educators' teaching season was completed at the time of this study, therefore observations were not conducted and interviews were conducted via telephone due to unfavorable weather conditions.
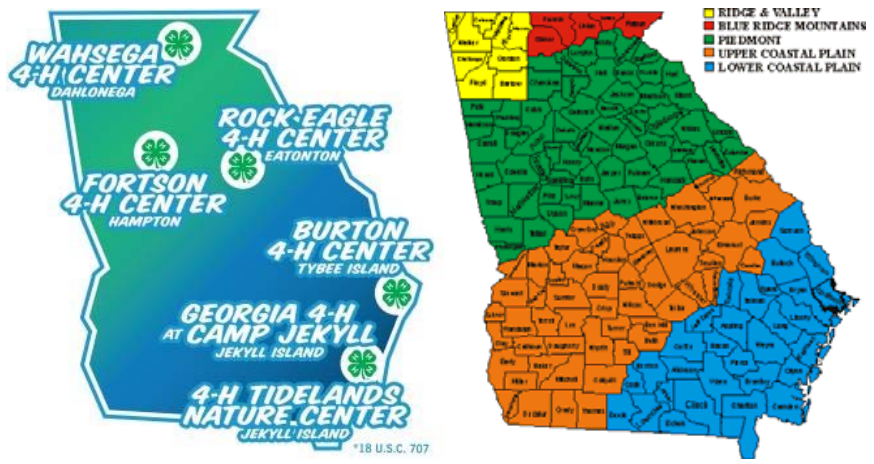

Figure 2. Location of 4-H EE centers and Georgia physiographic regions (Georgia 4-H, 2016; Georgia Department of Natural Resources, 2017). 
Table 1. Characteristics of Study Participants

\begin{tabular}{lllll}
$\begin{array}{l}\text { Participant } \\
\text { Pseudonym }\end{array}$ & Observation/Interview & Location & $\begin{array}{l}\text { Natural } \\
\text { Science/Non-Science }\end{array}$ & $\begin{array}{l}\text { Previous } \\
\text { Teaching } \\
\text { Experience } \\
\text { (years) }\end{array}$ \\
\hline Anna & Both & Rock Eagle (Piedmont) & Natural Science & 0 \\
Becky & Both & Rock Eagle (Piedmont) & Non-Natural Science & 0 \\
Charlotte & Both & Burton (Coastal) & Natural Science & 1 \\
Dorothy & Both & Burton (Coastal) & Non- Natural Science & 0.5 \\
Ellie & Interview only & Wahsega (Blue Ridge) & Natural Science & 2 \\
Fran & Interview only & Wahsega (Blue Ridge) & Natural Science & 3 \\
\hline
\end{tabular}

Note: All participants were female.

Observations were documented using an observation sheet (Figure 3) developed by the researcher based on the North American Association for Environmental Education (NAAEE) Guidelines for Excellence (2004). Additional notes were taken regarding other factors (i.e., weather, class size, chaperones, etc.) as observed by the researchers during the lesson. A research assistant with graduate work in EE accompanied the researcher during interviews and observations to aid in note taking, data interpretation, and debriefing. Both the researcher and research assistant came to an agreement on the decision to classify the educators' ability as "Not at all Effective" to "Extremely Effective" when completing the field observation sheet (Figure 3). Both the researcher and research assistant had training in non-formal teaching methods and aligned their observations with those explained in the NAAEE (2014) Guidelines for Excellence in Non-formal Education.

Field notes and interviews were transcribed and coded for reoccurring themes. The coding process, specifically, thematic analysis, was used in this study to identify reoccurring themes within the raw data using color coding. Reoccurring themes were listed in order of their prevalence in the raw data. Each interview was coded independently. After the initial coding, a cross case analysis was conducted. In the cross-case analysis, interviews, observations, and field notes were compared to each other and categorized into broader themes. These observations validated that the educators had applied the techniques and methods described during the interview.

Trustworthiness and Rigor. Trustworthiness and rigor must be considered in qualitative research to ensure the accuracy of the study findings (Lincoln \& Guba, 1985). This study took necessary steps to ensure trustworthiness and rigor, including: peer debriefing, clarifying researcher bias via subjectivity statements, member checking, and intercoder agreement (Creswell, 2007). During the data analysis process, the primary researcher, secondary researcher, and research assistant analyzed an interview and compared themes to establish intercoder agreement. The emerging themes were

\begin{tabular}{|c|l|l|l|l|l|}
\hline The educator was able to... & $\begin{array}{l}\text { Not at all } \\
\text { Effective }\end{array}$ & $\begin{array}{l}\text { Slightly } \\
\text { Effective } \\
\text { effective } \\
\text { or not } \\
\text { effective }\end{array}$ & $\begin{array}{l}\text { Somewhat } \\
\text { Effective }\end{array}$ & $\begin{array}{l}\text { Extremely } \\
\text { Effective }\end{array}$ & Notes \\
\hline $\begin{array}{c}\text {...set expectations and objectives } \\
\text { for the lesson }\end{array}$ & & & & & \\
\hline $\begin{array}{c}\text {...use an interest approach/hook } \\
\text { at the start of the lesson }\end{array}$ & & & & & \\
\hline $\begin{array}{c}\text {...encourage students to interact, } \\
\text { observe, and experience different } \\
\text { elements during the lesson }\end{array}$ & & & & & \\
\hline $\begin{array}{c}\text {...provide opportunities for } \\
\text { hands-on learning }\end{array}$ & & & & & \\
\hline $\begin{array}{c}\text {...provide a novel experience for } \\
\text { students }\end{array}$ & & & & & \\
\hline $\begin{array}{c}\text {...relate the information to the } \\
\text { students' everyday lives }\end{array}$ & & & & & \\
\hline
\end{tabular}

Figure 3. Sample items from the field observation sheet. 
consistent between researchers. The research assistant provided peer debriefing pre- and post-data collection. To minimize bias during data analysis, the researcher utilized a methodological journal. Additionally, the authors have provided a subjectivity statement to minimize bias in reporting. Furthermore, the interview guide used to facilitate the semi-structured interviews incorporated member checking. This technique allowed for study participants to provide feedback on the researchers' findings of the observation portion of the study and interview to ensure accuracy in data interpretation (Schwandt, 1997).

This study focused on environmental educators teaching at a 4-H EE center in Georgia from December 2016 to February 2017 and who have taught at the center for less than a year. The data were limited to the selected 4-H environmental educators in Georgia. The results from this study cannot be generalized beyond the population of this study due to the purposely selected population studied. The researchers were non-participant observers during the lesson presentations. Students, chaperones, and instructors were aware of the researchers during the lesson observations, but researcher/participant interaction during observations was minimal. During the post-lesson interview with educator participants, the researcher used member checking to validate the findings of the lesson observation and allow for opportunities to obtain other pertinent information about the lesson from the educator.

Subjectivity Statement. The lead author received a bachelor's degree in natural resources conservation with a focus on environmental education and a master's degree in agricultural and environmental education. She has worked in residential and day-use EE settings for three years. The second author is professor of environmental education and received undergraduate and master's degrees in forestry and a Ph.D. focused in agricultural and environmental education. He has over 20 years of experience in $\mathrm{EE}$ and has worked in both formal and nonformal settings teaching EE.

\section{Results}

After analyzing participant interviews and lesson observations, the researchers found that Georgia 4-H environmental educators believed "effective" teaching in environmental education was rooted in: novelty, student centered instruction, personalization of curriculum based on educator characteristics, management of the learning environment, use of extra resources, and student engagement and inclusion.

Novelty. Educators stated that EE programs are often novel to students. In this study, novelty was defined by the researchers as things considered to be new or different to the learners visiting the EE center, such as the environment, plants, animals, people, and culture of the area. Along with students experiencing an outdoor classroom, educators also attributed success to using novel and hands-on teaching tools. In the observed lessons, educators engaged students in multiple activities that are not typically experienced on a daily basis in Georgia public schools. Activities included a marsh scavenger hunt, practicing use of simple tools, identifying real algae under microscopes, and educational hikes. Participants explained that exposing students to new environments was one of the most impactful pieces of the program. Dorothy stated, "even if they [students] have been to the beach, they may not have been to the beach at night... for a night walk that can be a very special experience." Other participants mentioned that the novel experience for the students impacted their teaching. Charlotte shared, "I might be having a bad day, but I need to remember it's the kids' first time here, I need to pump up my attitude." The observed educators displayed high energy, positivity, and vast curriculum knowledge.

Additionally, study participants identified multiple teaching tools that aided in effective EE instruction. Participants believed the environment served as a visual aid and allowed students to vividly contextualize the presented information. Charlotte shared how the environment served as a teaching tool and stated, "until we [the class] get to the beach and are like okay, there's Hilton Head, there's where our sand comes from and they [students] are like wow, that's so far away!" Environmental educators also described the use of animals as teaching tools in their lessons. Ellie echoed, "it's one thing to talk about turtles and show people pictures of turtles, but it's totally different when they see one and they get to touch one." Study participants demonstrated the use of live plants and animals in their instruction during the lesson observations. Participants used domestic farm animals and wild animals such as snails, crabs, and spiders. Further, participants invited students to engage with plants specifically and believed this was a special, memorable element of their teaching. Burton 4-H Center educators provided opportunities to identify plants that classify marsh zones and allowed students to taste edible plants. Rock Eagle 4-H Center educators also used live plants (a bamboo forest) in their instruction to explain irrigation, flood water, and mosquito management.

Student Centered. Educators shared the importance of fostering both personal and environmental connections during EE lessons. Anna enjoyed "making connections on the walk up. I like to talk to the students and get out of that teacher mode." Ellie found that one unique piece of teaching at a 4-H center included "a lot of the classes were smaller, so you could learn a lot of the kids by name." In all four observations, each educator made a distinct effort at the start of the lesson to learn the names of each student and called on students by name during instruction. Dorothy stated that knowing students' names helped her to connect with students on a personal level and stated, "for me personally, a great teacher is one that 
can know the students by name and can have like one-onone conversations with them and can contribute to their personal development." Dorothy continued to explain the importance of connecting students to the environment and shared, "the most important thing in any education, like not just knowing the knowledge like, oh, I know what a cnidarian is, but knowing how to apply that to your life." Fran hoped her students remembered "how much they were outside and how much they enjoyed being outside and how cool they think the environment is."

Personal Teaching Style Development. Study participants stated that personalizing the curriculum based on their own traits and teaching styles was important to their success. Dorothy explained:

You have to cover certain things like for the curriculum, but you really have a lot of flexibility in the way you teach it. And we all have our own styles of teaching and that can be really rewarding because you can like tweak your teaching to see what students respond to the most.

Becky explained, "I feel like constantly growing...like if I learned something from that class that I can take forward, then I feel like it was pretty successful." Environmental educators also stated that personalizing the curriculum based on their own personalities and teaching methods was important to their perceptions of teaching success. Dorothy explained that she developed her own teaching style by "...mixing up how I teach it or the order just to see if the kids remember it better in a certain way. And I can test that along the way."

During lesson observations at both Rock Eagle and Burton 4-H Centers, the educators taught the same lesson, allowing the researchers to directly compare their teaching methods. At Rock Eagle 4-H Center, both educators taught a natural history lesson while at Burton 4-H Center, both educators taught a marsh ecology lesson. Although the base curriculum and training was identical for the educators, each lesson was delivered in a different style. Field notes revealed that Anna was more inquisitive of the students, engaged students in group challenges, and utilized chaperones as examples. Becky taught the same lesson, but took a more reserved approach, allowing the students to explore at times and engage in more solitary activities. At Burton, Charlotte used examples relevant to the students' lives, encouraged the students to remain engaged and active during the lesson, and demonstrated flexibility in teaching style. Alternatively, Dorothy was extremely high energy, broke down the concepts using diagrams, and encouraged students to participate in hands-on activities. Despite differences in delivery, each educator received an extremely effective rating on the observation sheet and observations of the student participants indicated that students seemed to enjoy their teaching and the lesson overall.
Management of the Learning Environment. Participants revealed that managing the class in the outdoor learning environment was especially important. Factors of managing the environment included chaperones, teaching mechanics, and safety/risk.

Chaperones. Study participants conveyed that chaperones played positive and negative roles in the learning environment. Anna explained that engaging the chaperones in the lessons while making personal connections aided in creating positive roles. Ellie also noted, "since they [chaperones] aren't teachers, they have a tendency to interrupt or interject in stories just as bad as the children do." Field notes from EE lesson observations revealed the impact of chaperones on the lesson. Some educators facilitated chaperone involvement by providing chaperones with roles during the lesson. However, some chaperones were uninterested and disconnected from the lesson and student engagement all together.

Teaching mechanics. Educators shared specific techniques that they found successful in their teaching. Becky detailed, "I like to move around amongst the kids, the students." Charlotte found "having a story teller voice" kept students engaged in the lesson. Charlotte expanded, "I always try to have the confident stage posture, but also try to lean forward and draw them in that way." Ellie mentioned, "making eye contact with their kids. And I really like animated language." Field notes from lesson observations found that built-in structures, such as logs and rocks suited for student seating, aided in management of the learning environment.

Safety/risk. The educators also stated the importance of managing risk outdoors. Fran noted that "safety of the kids is always an important thing before you can teach them anything." Ellie also emphasized the importance of preparedness in safety because:

A lot of times what makes the parents nervous, what they are really worried about, are like emergency situations. So letting them know like hey, we will have a radio, we are only 10 minutes from the center, and if anything happens, we will immediately be able to take care of it.

Extra Resources. Participants shared that taking advantage of resources and other educators on-site was important to their development. Educators revealed that they continued to research and learn about content after training was complete. Non-science background educators revealed that they typically spent more time preparing for lessons than science background educators. Seeking extra resources and complementary information in addition to the mandatory curriculum allowed educators to speak more broadly and confidently about topics. Ellie noted that having more information allowed her to be more confident and enthusiastic and stated, "it's not so much what you are talking about as much as how you are talking about it." However, educators also shared that working together to learn the material and how to best teach curriculum aided in their individual teaching 
style development. Charlotte believed, "being able to talk to others about how they do it [teach], and kind of stealing how they do it, that's really helpful." Dorothy echoed this idea and asserted, "I just try to use as many resources as possible, whether its books or the other environmental educators like oh, how do you teach this class? Like are there any approaches you use to teach this?" This teaching support group for sharing also seemed to enhance rapport and morale among the educators.

Student Engagement and Inclusion. The final theme that emerged from the data regarded the engagement of students in the outdoor setting and inclusion of students in scientific fields. Educators felt most excited and effective in their teaching when students were actively engaged and excited to learn. The study participants shared that they hoped the EE experience helped all students to be included in the scientific field. Educators believed great teaching happened when students were engaged and excited during the lesson. Anna shared she felt successful "when they are excited to be involved in the class and almost sad to go." While Fran stated, "I think if the kids are like... animated and excited. Like when they leave your class and the kids are just like really pumped...that's when you know you've succeeded." One goal of educators was to increase student self-efficacy in science fields after the EE experience. Becky shared one instance that was particularly memorable and indicated that her EE instruction was effective:

At the end of class, a little boy came up to me and he was like Miss Becky...in school I'm failing science and I just don't know any of the answers....and I'm just doing really badly, but here it seems like I know all the answers and I've learned so much.

\section{Conclusions and Recommendations}

Previous studies have emphasized the need to understand EE program inputs (Goldsmith \& Rubenstein, 2017; Stern et al., 2014) with less emphasis on the characteristics of the educator and their teaching methods. Seminal works have noted that the educator has remained one of the most influential inputs to any educational program or lesson (Rosenshine \& Furst, 1971). Participants in this study found capitalizing on the novelty of the environment and teaching tools attributed to their perceived success. The novel EE outdoor learning setting seemed to set educators up for success in their teaching. However, if the educator is unable to effectively manage the class, students can easily become distracted while heightening risk. Participants in this study revealed that an effective environmental educator must be able to foster not only an environmental connection, but also a personal connection between the educator and students. Educators worked to develop personal connections during short lessons through the use of student names. In addition, the use of hands-on, interactive, novel, and visual teaching tools allowed educators to engage students in lessons that spark a connection between the students and the environment.

Environmental connection was more heavily emphasized by participants than content knowledge and skills. In essence, it was less important to participants of this study that they knew all of the facts about the environment to share with students at the 4-H Center as it was to foster a meaningful, relevant connection between students and the natural world. Participants believed that if they were effective in their teaching, students would actively seek information about the environment after they left the 4-H Center and would be more likely to pursue a science or environmentallyrelated career because of their teaching. While environmental connection is key in $\mathrm{EE}$, content knowledge and skill sets must be emphasized by educators to foster environmental appreciation, and ultimately, pro-environmental action (NAAEE, 2010).

Educators' teaching style and methods were also affected by their personal backgrounds and characteristics. Over time, each educator in this study developed their own teaching style by interacting with educators with different backgrounds and characteristics. Encouraging non-natural science background students to pursue short term environmental experiences may help spark an interest in EE careers. Non-natural science background educators mentioned that they felt the need to prepare heavily and study the material more before teaching lessons. However, these educators also believed that since content was recently learned during their training, they were better able to communicate simply to students. Natural science background educators seemed to prefer less structured lessons that capitalized on "teachable moments" presented by the environment. However, all educators mentioned the importance of being able to draw from a wide variety of resources, including other educators, to inform their own professional development as teachers. Participants noted that by talking to other educators about teaching challenges and strengths, this helped develop their own teaching methods and styles based on their own personalities.

This study further highlighted the similarities between EE and career and technical education from a teaching and learning standpoint. Both disciplines are grounded in experiential education, learner-centered, often place-based, and require educators with the skills to capitalize on "teachable moments" that often arise outside of the classroom. Shumacher et al. (2012) noted the similarities between EE and career and technical education and encouraged addition collaboration between the disciplines. Environmental education program developers, 4-H Center directors, and career and technical agricultural educators should allow in-service and pre-service environmental educators to practice and adapt curriculum to their own personal teaching styles and provide arenas for individual and group evaluation and reflection. Fuhrman and Rubenstein (2017) found 
that providing pre-service environmental educators with opportunities to practice and reflect on their teaching before their peers promoted flexibility and reduced anxiety among educators. Researchers should continue to explore effective teaching methods in EE, characteristics and personal traits of environmental educators, EE inputs, and student perceptions of effective teaching in EE. For example, all participants in this study were female and additional exploration of male educators may further add to the EE and career and technical education research base. These findings are critical to inform the training and hiring protocols of environmental educators through the development of effective EE teaching methods that will aid in creating the most impactful learning experiences for students.

\section{References}

Ballantyne, R., \& Packer, J. (2002). Nature-based excursions: School students' perceptions of learning in natural environments. International Research in Geographical and Environmental Education, 11(3), 218-236.

Barrick, R.K., \& Thoron, A.C. (2016). Teaching behavior and student achievement. Florida Cooperative Extension Service Electronic Data Information Source AEC582: Retrieved from http://edis.ifas.ufl.edu/wc244

Bandura, A. (1971). Social learning theory. Morristown, N.J.: General Learning Press.

Bandura, A. (2004). Model of causality in social learning theory. In A. Freeman, M. J. Mahoney, P. DeVito, D. Martin (Eds.), Cognition and Psychotherapy (2nd ed., pp. 25-44). New York, NY: Springer.

Chambers, J. M., \& Radbourne, C. (2014). Teaching critical literacy skills through the natural environment "as" text. Applied Environmental Education and Communication, 13(2), 120-127.

Creswell, J. W. (2007). Qualitative inquiry \& research design: Choosing among five approaches (3rd ed.). Thousand Oaks, CA: Sage Publications.

Coombs, P., and Ahmed, M. (1974). Attacking rural poverty: How nonformal education can help. Baltimore, MD: Johns Hopkins University Press.

Digby, J. K., \& Ferrari, T. (2007). Camp counseling and the development and transfer of workforce skills: The perspective of Ohio 4-H camp counselor alumni. Journal of Youth Development, 2(2), 101119.

Franz, N., Garst, B., Baughman, S., Smith, C., \& Peters, B. (2009). Catalyzing transformation: Conditions in extension educational environments that promote change. Journal of Extension, 47(4), 1-8.

Fuhrman, N. E., \& Rubenstein, E. D. (2017). Teaching with animals: The role of animal ambassadors in improving presenter communication skills. Journal of Agricultural Education, 58(1), 223-235. https:// doi.org/10.5032/jae.2017.01223

Georgia 4-H. (2016). Environmental education at Georgia 4-H centers. Retrieved from http://www .Georgia4h.org/ee/

Georgia 4-H. (2016a). About Georgia 4-H. Retrieved from http://www.Georgia4h.org/main/about4h.cfm

Georgia 4-H. (2016b). Environmental education at Georgia 4-H centers. Retrieved from http://www .Georgia4h.org/ee/

Georgia 4-H. (2016c). Georgia 4-H summer camp. Retrieved from http://Georgia4h.org/camp/

Georgia Department of Natural Resources. (2017). Geographic regions of Georgia. Retrieved from http://Georgiawildlife.dnr.state.ga.us/assets/images 1148.png

Goldsmith, H. L., \& Rubenstein, E. D. (2017). An integration of outdoor classrooms into schools: A synthesis of literature. Research Conference Proceedings Southern Region Held in Conjunction with the Meeting of the Southern Association of Agriculture Scientists (SAAS), Mobile, AL. 199216.

Lerner, R. M., \& Lerner, J. V. (2013). The positive development of youth: Comprehensive findings from the 4-H study of positive youth development. Tufts University.

Lieberman, G. A., \& Hoody, L. L. (1998). Closing the achievement gap: Using the environment as an integrating context for learning. San Diego: State Education and Environmental Roundtable.

Lincoln, Y. S., \& Guba, E. G. (1985). Naturalistic Inquiry. Newbury Park, CA: SAGE Publications.

Minor, L. C., Onwuegbuzie, A. J., Witcher, A. E., \& James, T. L. (2002). Preservice teachers' educational beliefs and their perceptions of characteristics of effective teachers. The Journal of Educational Research, 96(2), 116-127. https://doi .org/10.1080/00220670209598798

NAAEE. (2010). Excellence in environmental education: Guidelines for learning (K-12). Washington, D.C.: North American Association for Environmental Education.

National 4-H. (2015). About 4-H. Retrieved from http:// www.4-h.org/about/

Roberts, T. G., Dooley, K. E., Harlin, J. F., \& Murphrey, T. P. (2007). Competencies and traits of successful agricultural science teachers. Journal of Career and Technical Education, 22(2).

Rosenshine, B., \& Furst, N. (1971). Research on teacher performance criteria. Research in Teacher Education: A Symposium. Englewood Cliffs, NJ: Prentice-Hall, 37-72.

Schwandt, T. A. (1997). Qualitative inquiry: A dictionary of terms. Thousand Oaks, CA: Sage Publications.

Shumacher, S., Fuhrman, N. E., \& Duncan, D. W. (2012). The influence of school culture on environmental education integration: A case study 
of an urban private school system. Journal of Agricultural Education, 53(4), 141-155.

Smith, M. K. (2002). Informal, non-formal, and formal education: A brief overview of different approaches. Retrieved from http://infed.org/mobi /informal-non-formal-and-formal-education-abrief-overview-of-some-different-approaches/

Taylor, E.W., \& Caldarelli, M. (2004). Teaching beliefs of non-formal environmental educators: A perspective from state and local parks in the United States. Environmental Education Research, 10(4), 451-469.

UNESCO-UNEP. (1978). Final report: Intergovernmental conference on environmental education, Paris: UNESCO ED/MD/49. Organized by UNESCO in Cooperation with UNEP, Tbilisi, USSR. 